\title{
Effect of Chinese Herb Extract on the Formation of Triterpenoids in Shake-Flask Cultures of Antrodia cinnamomea
}

\section{Te-Wei Ma ${ }^{1}$, Ning-Ju Yang ${ }^{2}$ and Fan-Chiang Yang ${ }^{2 \star}$}

${ }^{1}$ Department of Chemical Engineering, Army Academy, Taoyuan 32092, Taiwan

${ }^{2}$ Department of Chemical and Materials Engineering, Tunghai University, Taichung 40704, Taiwan

\begin{abstract}
Antrodia cinnamomea is a well-known medicinal mushroom producing potent bioactive triterpenoids; it only grows in Taiwan. Its anti-tumor activity remains the focus of current research on triterpenoids. However, a main drawback of producing mycelia by submerged cultures is the rather low levels of triterpenoid produced. In this research, different kinds of Chinese herb water extracts were added into the media to study their effects on the formation of triterpenoids of $A$. cinnamomea in the thin stillage submerged cultures. Astragalus water extract was the most effective for enhancing triterpenoids production. With an addition of Astragalus water extract of $2 \%(\mathrm{v} / \mathrm{v})$, the content and concentration of triterpenoids were $10.36 \mathrm{mg} / \mathrm{g}$ DW and $85.28 \mathrm{mg} / \mathrm{L}$, respectively, which were 3-fold and 5 -fold higher than the control, respectively, on the $21^{\text {th }}$ day. The results reveal that although the addition of Chinese herb water extract lengthens the exponential phase and reduces the specific growth rate, the production rate of biomass, intracellular polysaccharide (IPS) and triterpenoids were still significantly enhanced. Moreover, this study also demonstrates the feasibility of reusing thin stillage for the mycelia culture of $A$. cinnamomea.
\end{abstract}

Keywords: Antrodia cinnamomea; Triterpenoids; Chinese herb; Thin stillage; Submerged cultures

\section{Introduction}

Antrodia cinnamomea is a parasitic fungus found exclusively on the inner wall of the endemic species Cinnamonum kanehirai Hay. It is commonly used as a traditional Chinese remedy for alcohol and drug intoxication, hypertension, abdominal pain and cancer $[1,2]$ and recently becomes the most expensive medicinal mushroom in Taiwan. Many researchers have revealed that A. cinnamomea possesses antioxidant, antitumor and immunomodulating activities. Various types of bioactive compounds from the fruiting bodies of $A$. cinnamomea have been identified, including triterpenoids, polysaccharide, steroids and sesquiterpene lactone [1,3-5]. Apart from polysaccharide, triterpenoids were well recognized as potential anticancer agents due to their activity against growing tumors in the fruiting bodies of A. cinnamomea $[1,3,5$ 8]. Cultivated mycelium has been reported to exhibit similar anticancer effects with wild fruiting bodies [9-13]. Owing to exhibiting such physiological functions, the determination of cultivation strategies by controlling culture conditions or modifying media compositions deserves detailed study in order to improve the production of triterpenoid.

Since natural A. cinnamomea in the wild grows very slowly and takes many years to form fruiting bodies, submerged cultivation has developed as an alternative to commercial practice at the present time. The use of submerged cultures provides some potential advantages, including higher mycelia production rate in a more-compact space over a shorter time with a lower chance of contamination; it is the preferred route for the production of some valuable metabolites. In order to enhance production efficiency, the modification of media compositions or the control of environmental conditions is vital. The research of Chang and Wang demonstrated that the addition of bark extract or wood chips of Cinnamomum kanehirai Hay was beneficial to the growth of A. cinnamomea in mycelia cultures [14-17]. However, this idea would never be practical due to the slow growth of Cinnamomum kanehirai Hay. Therefore, finding a substitute for wood chips deserves further study.

Our previous work demonstrated that citrus peel extract additive can effectively enhance the production of biomass and bioactive metabolites in the submerged cultures or solid-state fermentation of $A$. cinnamomea [18-20]. Dry citrus peel has been used as a kind of Chinese herbal medicine. Most Chinese herbs that have a special smell are the most similar to bark extract or the wood chips of C. kanehirai Hay. Chinese herbs have been used as food and for medicinal purposes for centuries, in which contain many compounds that may be relevant to the medicine's putative activity. Research interest has focused on various herbs that possess antitumor, hypolipidemic or immune-stimulating properties that may be useful adjuncts in helping to reduce the risk of cancer and cardiovascular disease. Traditionally, Chinese herbs have a history of safe and effective treatment of many diseases [21-23]. Among many sources, Chinese herbs are obviously the safest and healthiest source.

Rice spirit is a distilled alcoholic beverage in Taiwan, and has been mainly used for Chinese cooking. During its manufacture process, large volumes of wastewater were produced and known as thin stillage, which is rich in carbon sources and organic acids. Owing to the characteristics of high organic content and low $\mathrm{pH}$, thin stillage is difficult to treat. Therefore, developing an effective process for reutilization of the distillery wastewater is highly desired [24-28]. In the study, thin stillage

*Corresponding author: Fan-Chiang Yang, Department of Chemical and Materials Engineering, Tunghai University, Taichung 40704, Taiwan, Tel: 886423590214; Fax: 886423590009; E-mail: fcyang@thu.edu.tw

Received June 19, 2017; Accepted July 06, 2017; Published July 12, 2017

Citation: Ma TW, Yang NJ, Yang FC (2017) Effect of Chinese Herb Extract on the Formation of Triterpenoids in Shake-Flask Cultures of Antrodia cinnamomea. J Bioprocess Biotech 7: 307. doi:10.4172/2155-9821.1000307

Copyright: @ 2017 Ma TW, et al. This is an open-access article distributed unde the terms of the Creative Commons Attribution License, which permits unrestricted use, distribution, and reproduction in any medium, provided the original author and source are credited. 
was reused for A. cinnamomea mycelial culture to investigate the influences of adding Chinese herb water extract on the mycelia growth and bioactive component production.

\section{Materials and Methods}

\section{Organism and inoculum}

The organism used in this study was Antrodia cinnamomea CCRC35396, which was obtained from the Bioresources Collection and Research Center (BCRC) (Hsinchu, Taiwan). The strain was maintained on potato dextrose agar (PDA) slants, which were incubated at $25^{\circ} \mathrm{C}$ for 7 days. The organism was then stored at $4^{\circ} \mathrm{C}$ and usually transferred to a fresh agar plate every two months.

\section{Inoculum preparation}

The liquid medium for seed culture was made up of the following components $(\mathrm{w} / \mathrm{v})$ : glucose $2.0 \%$, malt extract $2.0 \%$ and peptone $0.1 \%$. After sterilization at $121^{\circ} \mathrm{C}$ for $20 \mathrm{~min}$., A. cinnamomea mycelia were transferred to the liquid medium by punching out $0.7 \mathrm{~cm}$ diameter agar discs from mycelia culture grown on PDA plates. Four discs were used to inoculate $100 \mathrm{~mL}$ liquid media in a $250 \mathrm{~mL}$ shake flask and the seed culture was then carried out at $25^{\circ} \mathrm{C}, 100 \mathrm{rpm}$ for 7 days.

\section{Shake flask cultures}

The shake flask cultures were carried out in $250 \mathrm{~mL}$ Erlenmeyer flasks containing $100 \mathrm{~mL}$ of basal medium inoculated with $10 \%$ $(\mathrm{v} / \mathrm{v})$ of the seed culture. The thin stillage was provided by Taichung Distillery (Taiwin Tobacco and Liquor Corporation) and prepared by filtration with filter pore size of $6 \mu \mathrm{m}$, which was then used directly as the basal medium in a flask culture. Apart from the basal medium, various kinds or concentrations of Chinese herb water extracts were added into the medium to study their influence on the production of bioactive metabolites. After sterilization at $121^{\circ} \mathrm{C}$ for $20 \mathrm{~min}$., the culture was incubated at $25^{\circ} \mathrm{C}, 100 \mathrm{rpm}$ for 35 days, and samples were collected at various intervals for analyzing biomass concentration, intracellular polysaccharides (IPS) concentration and the contents of total polyphenol and triterpenoids. The data shown are the means of triplicate determinations.

\section{Preparation of Chinese herb water extracts}

Five kinds of Chinese herbs (Star anise, Fagara, Astragalus, Turmeric and Cinnamon) were purchased from a local Chinese herbal medicine shop; $50 \mathrm{~g}$ of Chinese herb were mixed with one liter of water, and the mixture was then boiled for $3 \mathrm{~h}$. After filtration with 100 mesh sieves, the extract was concentrated to 10 -fold by using a vacuum evaporator and then stored at $4^{\circ} \mathrm{C}$

\section{Determination of Intracellular Polysaccharides (IPS)}

Intracellular polysaccharides were extracted from dried mycelia $(100 \mathrm{mg}$ ) by suspending the mycelia in $10 \mathrm{~mL}$ of distilled water and autoclaving at $15 \mathrm{psi}, 121^{\circ} \mathrm{C}$ for $20 \mathrm{~min}$ [27]. Samples from the shake flasks were centrifuged at $8000 \mathrm{rpm}$ for $10 \mathrm{~min}$, and the supernatant obtained was then mixed with four volumes of $95 \%$ (v/v) ethanol, stirred vigorously and left overnight at $4^{\circ} \mathrm{C}$. The precipitated polysaccharide was collected by centrifugation at $8000 \mathrm{rpm}$ for $10 \mathrm{~min}$ and then lyophilized to remove residual ethanol. Total polysaccharide in the culture medium was determined by phenol-sulfuric acid assay according to Dubois et al. [29].

\section{Measurements of crude triterpenoid and total polyphenol}

The dried mycelia (100 mg) were extracted by $50 \%(\mathrm{v} / \mathrm{v})$ ethanol (3 $\mathrm{mL}$ ) for one week (twice) for the determination of crude triterpenoid. The crude triterpenoid content was analyzed by the method described in the paper of Tsujikura et al. [30]. For the assay of total polyphenol, the dried mycelia $(100 \mathrm{mg})$ were extracted by methanol $(20 \mathrm{~mL})$ for $12 \mathrm{~h}$ at $50^{\circ} \mathrm{C}$. The total polyphenol content was analyzed according to the method of Singleton and Rossi [31] with a slight modification. The detailed analysis procedures were the same as those described in our previous papers [18-20].

\section{HPLC system for the analysis of triterpenoid}

The dried mycelia (100 mg) were extracted by $50 \%(\mathrm{v} / \mathrm{v})$ ethanol (3 $\mathrm{mL}$ ) for $12 \mathrm{~h}$, and the extraction was assisted by successive sonication using Delta D200H Sonication Cleaner for the HPLC analysis of triterpenoid. The pretreatment procedures were the same as those described in our previous papers $[19,20]$.

According to the paper by Chang et al. in 2011 [32], the method for the analysis of triterpenoid was modified and HPLC analysis was performed on an Agilent 1100 series with UV detection. The detection wavelength was set to $254 \mathrm{~nm}$. Separation was obtained with a reversedphase column (Cosmosil 5C18- AR-II, $250 \times 4.6 \mathrm{~mm}$, Kyoto, Japan) eluted at a flow rate of $1 \mathrm{ml} \mathrm{min}{ }^{-1}$ with a linear solvent gradient elution of $\mathrm{A}\left(0.0085 \% \mathrm{H}_{3} \mathrm{PO}_{4}\right.$ in $\left.\mathrm{H}_{2} \mathrm{O}\right)$ and $\mathrm{B}$ (acetonitrite). The column was eluted according to the following profile: 0 65 $\mathrm{min}, 30 \sim 47 \% \mathrm{~B}, 65 \sim 110$ min, $47 \sim 47 \%$ B, $110 \sim 140 \mathrm{~min}, 47 \sim 100 \%$ B, $140 \sim 160 \mathrm{~min}, 100 \sim 100 \%$ B, 160 165 min, 100 30\% B, 165 180 min, 30 30\% B. The column temperature was set to $30^{\circ} \mathrm{C}$. The injection volume was $20 \mu \mathrm{L}$.

\section{Statistical analysis}

Variations between experiments were displayed from standard deviations, and the statistical significance of changes in the physiological parameters was also calculated using the Student's t-test. In all the graphs, the symbol ${ }^{\star}$ indicates a significant difference to the untreated groups, $\mathrm{p}<0.05 ;{ }^{* *}$ indicates a significant difference to the untreated groups, $\mathrm{p}<0.01$. All data were the means of three measurements.

\section{Results and Discussion}

\section{Batch flask culture}

The kinetics of mycelia growth and metabolite accumulation by $A$. cinnamomea in shake flask cultures is displayed in Figure 1. The control

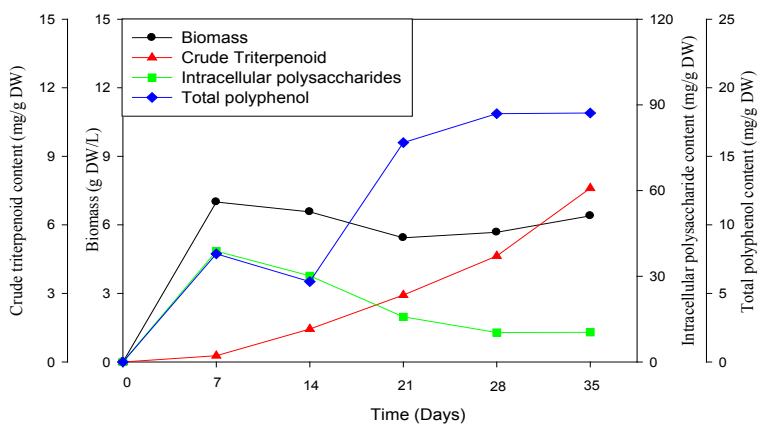

Figure 1: Time course of mycelial growth and metabolite formation during submerged fermentation of $A$. cinnamomea by reusing thin stillage at $25^{\circ} \mathrm{C}$ for 35 days. 
culture was carried out in a $250 \mathrm{ml}$ flask with $100 \mathrm{~mL}$ of basal medium (thin stillage) at initial pH $3.5,25^{\circ} \mathrm{C}$ and $100 \mathrm{rpm}$ for 35 days. The data indicate that the biomass and intracellular polysaccharide concentrations increased rapidly within the first 7 days, during which time the cells were in the exponential growth phase. According to the results shown in Figure 1, intracellular polysaccharide appears to be a growth-associated product. The mycelia biomass and IPS concentrations achieved the highest levels on day 7 , and the corresponding maximum values were $7.00 \mathrm{~g}$ DW/L and $38.80 \mathrm{mg} / \mathrm{g}$ DW, respectively. On the contrary, crude triterpenoid and total polyphenol did not formed proportionally to the mycelia growth and displayed a pattern of mixed-growth-associated products. Their concentrations rose to the highest values of $7.60 \mathrm{mg} / \mathrm{g}$ DW and $18.16 \mathrm{mg} / \mathrm{g}$ DW, respectively, on day 35 .

\section{Effect of addition of Astragalus water extract}

The time profiles of concentrations of biomass and metabolite produced in the culture with the addition of Astragalus water extract of $2 \%(\mathrm{v} / \mathrm{v})$ is displayed in Figure 2. Compared with the control demonstrated in Figure 1, it is interesting to note that there were great differences regarding the tendency of cell growth and bioactive metabolites formation during days 7 and 21. The mycelia even continued to grow until day 14 , when the highest concentration of 8.80 g DW/L was obtained. The intracellular polysaccharide concentration rose to $71.16 \mathrm{mg} / \mathrm{g}$ DW on day 7 with a two-fold increase. Moreover, the amount of crude triterpenoid achieved $10.36 \mathrm{mg} / \mathrm{g}$ DW on day 21 , with a more than three-fold increase (control on day 21). In contrast, the amount of total polyphenol reached $15.31 \mathrm{mg} / \mathrm{g}$ DW on day 21 , which showed only a slight decrease. The data demonstrate that the addition of Astragalus water extract had a great influence on cell physiology, and could effectively enhance the formation of secondary metabolites.

\section{Effect of various kinds of Chinese herb water extracts}

In addition to Astragalus, the influences of other Chinese herb water extracts, including Star anise, Fagara, Turmeric and Cinnamon, were also studied for comparison. Figure 3 indicates the influence of different kinds of Chinese herb water extracts on mycelial growth, intracellular polysaccharide and total polyphenol production. All additives caused an extension of the exponential phase and seemed to be benefit the mycelial growth, but Turmeric and Cinnamon water extracts were found to exhibit no effect on the production of polysaccharide. In contrast, all the additives seemed to slightly decrease the content of total polyphenol. Among the five Chinese herb water extracts tested, Star anise and Astragalus water extracts demonstrated to be the most valid in improving the production of bioactive metabolite. The content of intracellular polysaccharide content reached $73.32 \mathrm{mg} / \mathrm{g}$ DW (Star

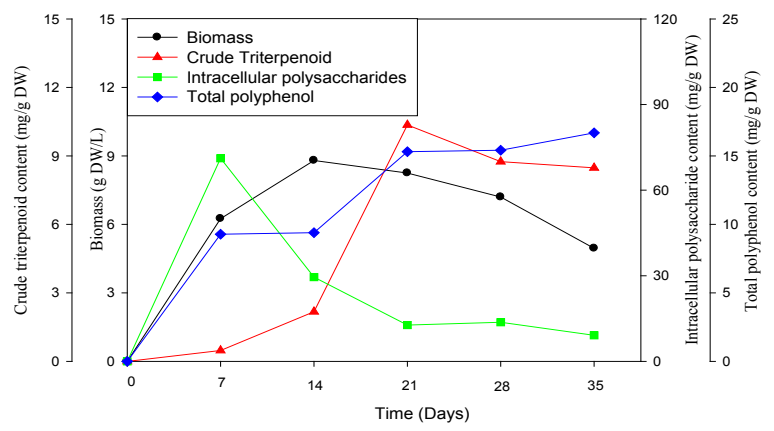

Figure 2: Time course of mycelial growth and metabolite formation of $A$. cinnamomea in a thin stillage submerged culture with the addition of Astragalus water extract $(2 \%(\mathrm{v} / \mathrm{v}))$ at $25^{\circ} \mathrm{C}$ for 35 days. anise) and $71.16 \mathrm{mg} / \mathrm{g}$ DW (Astragalus), representing $89 \%$ and $84 \%$ increase, respectively, compared with the control group.

Based on the data obtained on day 21, Figure 4 indicates the influence of various kinds of Chinese herb water extracts on the content and production of crude triterpenoid. With the exception of Fagara, the addition of Chinese herb water extracts appeared beneficial in regard to the crude triterpenoid content in the mycelium. Among the five Chinese herb water extracts tested, Astragalus water extracts was the most effective in enhancing the production of crude triterpenoid. Crude triterpenoid content reached $10.36 \mathrm{mg} / \mathrm{g}$ DW, representing nearly a 3.5-fold increase compared with the control group. Moreover, the production of crude triterpenoid rose from $16.00 \mathrm{mg} / \mathrm{L}$ in the control to $85.28 \mathrm{mg} / \mathrm{L}$, with a more than five-fold increase. The test demonstrated that Chinese herb water extracts tended to prolong the exponential phase and also accelerated the formation of crude triterpenoid in mycelium on day 21 .

\section{Effect of concentrations of Astragalus water extracts}

Different ratios of Astragalus water extract, ranging from 0.5 to $4 \%$ (v/v), were added into the media to study the effect of concentration, and also to determine an appropriate amount. In accordance with the results displayed in Figure 5A, the mycelia can grow with various amounts of Astragalus water extract, and total polyphenol content still reached a similar level to that of the control. Figure $5 \mathrm{~B}$ exhibits that total polyphenol production reached the highest concentration of 125.87 $\mathrm{mg} / \mathrm{L}$ at an addition level of $2 \%(\mathrm{v} / \mathrm{v})$ on day 21 , representing a $46 \%$ increase as compared with the control group.

The effect of the concentration on the formation of crude triterpenoid is presented in Figure 6. A 2\% (v/v) addition of Astragalus water extract demonstrated to be the most effective concentration; it could achieve the highest crude triterpenoid content of $10.36 \mathrm{mg} / \mathrm{g} \mathrm{DW}$ and maximum crude triterpenoid production of $85.28 \mathrm{mg} / \mathrm{L}$ on day 21 .

Astragalus membranaceus are among the most popular healthpromoting herbs in China; their use dates back more than 2000 years. Astragalus species are the richest source of cycloartanes; the unique triterpenoids have a characteristic 9,19-cyclopropane ring, and cycloastragenol, a key intermediate in the biosynthesis of different phytosterols [33-35]. In Kuban's study, a rearrangement to provides a novel triterpene framework via a ring cleavage (cycloastragenol) followed by a methyl migration, demonstrating once more the potential of the microbial systems and Cunninghamella blakesleeana for the transformation of bioactive molecules [36]. Cycloastragenol was subjected to microbial transformation studies using C. blakesleeana and Glomerella fusarioides fungi, and Nocardia sp., Mycobacterium sp. 3683 and Mycobacterium sp. bacteria. The two fungi mainly provided hydroxylated metabolites together with products formed by dehydrogenation, cyclization and oxidation of Baeyer-Villiger, leading to a ring cracking [35,37]. It is an important reason why the addition of Astragalus water extract achieved the highest crude triterpenoid content.

\section{Comparison of fermentation kinetic parameters}

Tables 1 and 2 indicate fermentation kinetics parameters of all the shake flask cultures for comparison. Chinese herb water extracts added into the media obviously caused a great influence on mycelia growth and metabolite formation. Concerning the crude triterpenoid production rate, as can be seen in Table 1, Fagara was the only Chinese herb that had a negative effect. In contrast, Astragalus water extract $(2 \%(\mathrm{v} / \mathrm{v}))$ can effectively enhance the production rate of crude triterpenoid from 1.35 
Citation: Ma TW, Yang NJ, Yang FC (2017) Effect of Chinese Herb Extract on the Formation of Triterpenoids in Shake-Flask Cultures of Antrodia cinnamomea. J Bioprocess Biotech 7: 307. doi:10.4172/2155-9821.1000307

(A)

(B)

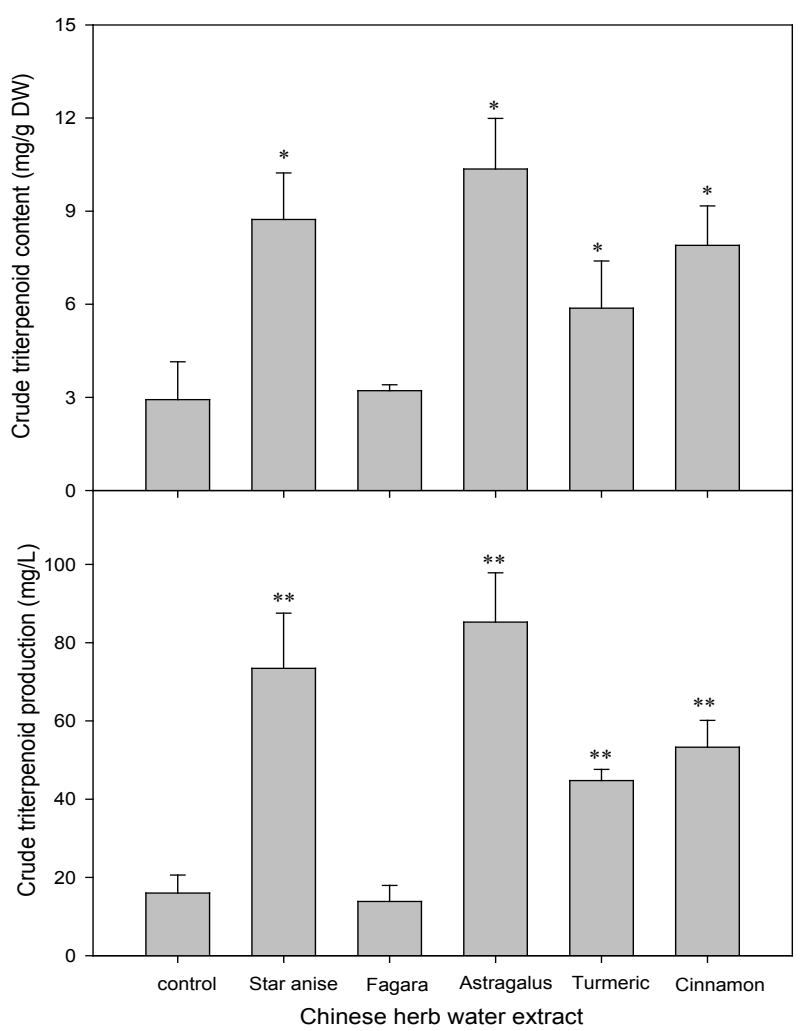

Figure 3: Effect of different kinds of $2 \%$ (v/v) Chinese herb water extract on the biomass for 14 days (A), Intracellular polysaccharides for 7 days (B) and total polyphenol for 21 days $(\mathrm{C})$ by reusing thin stillage at $25^{\circ} \mathrm{C}$

(A)

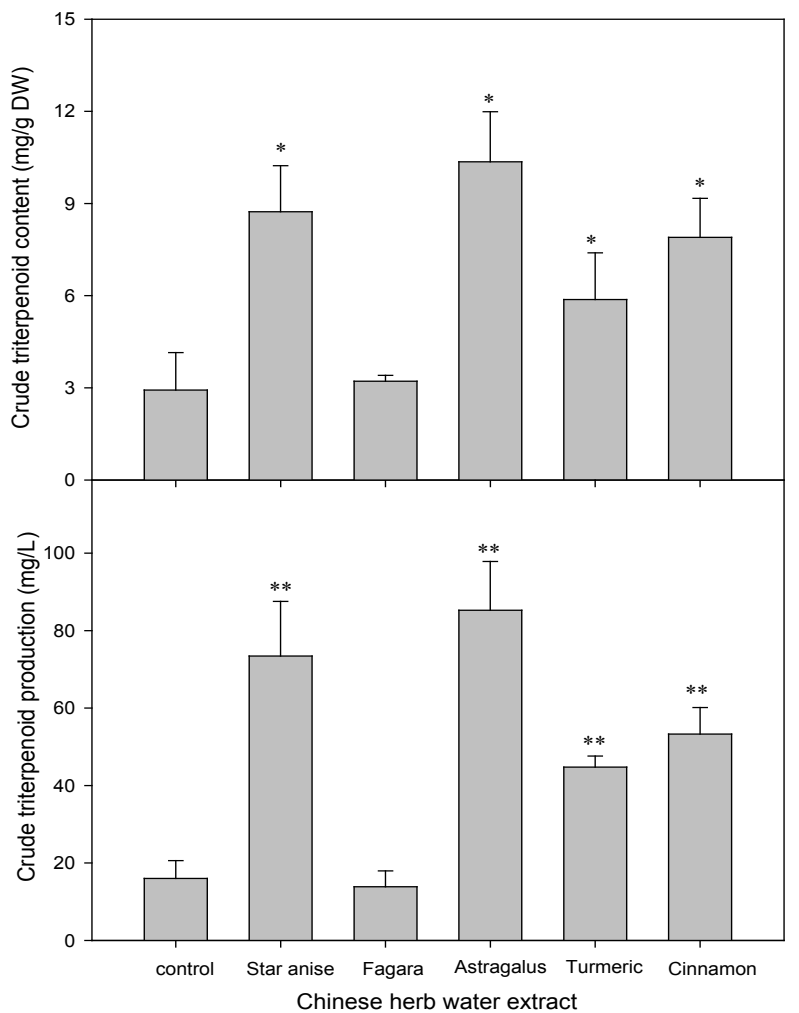

Figure 4: Effect of different kinds of $2 \%(\mathrm{v} / \mathrm{v})$ Chinese herb water extract on the content $(\mathrm{A})$ and production $(\mathrm{B})$ of triterpenoid by reusing thin stillage at $25^{\circ} \mathrm{C}$ for 21 days. 
Citation: Ma TW, Yang NJ, Yang FC (2017) Effect of Chinese Herb Extract on the Formation of Triterpenoids in Shake-Flask Cultures of Antrodia cinnamomea. J Bioprocess Biotech 7: 307. doi:10.4172/2155-9821.1000307

(A)

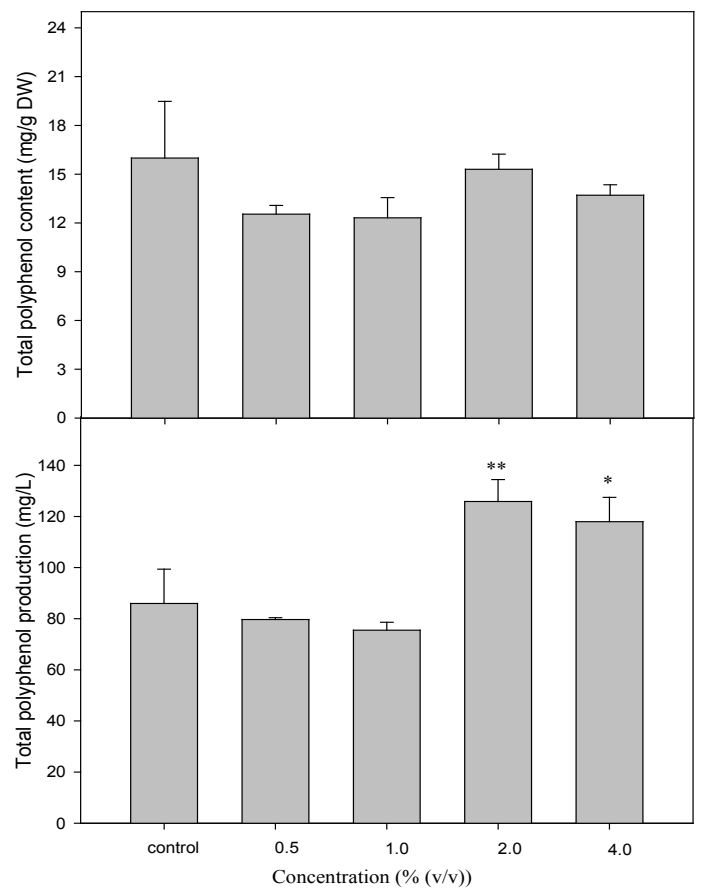

Figure 5: Effect of different concentrations of Astragalus water extract on the content $(A)$ and production (B) of total polyphenol by reusing thin stillage at $25^{\circ} \mathrm{C}$ for 21 days.

(A)

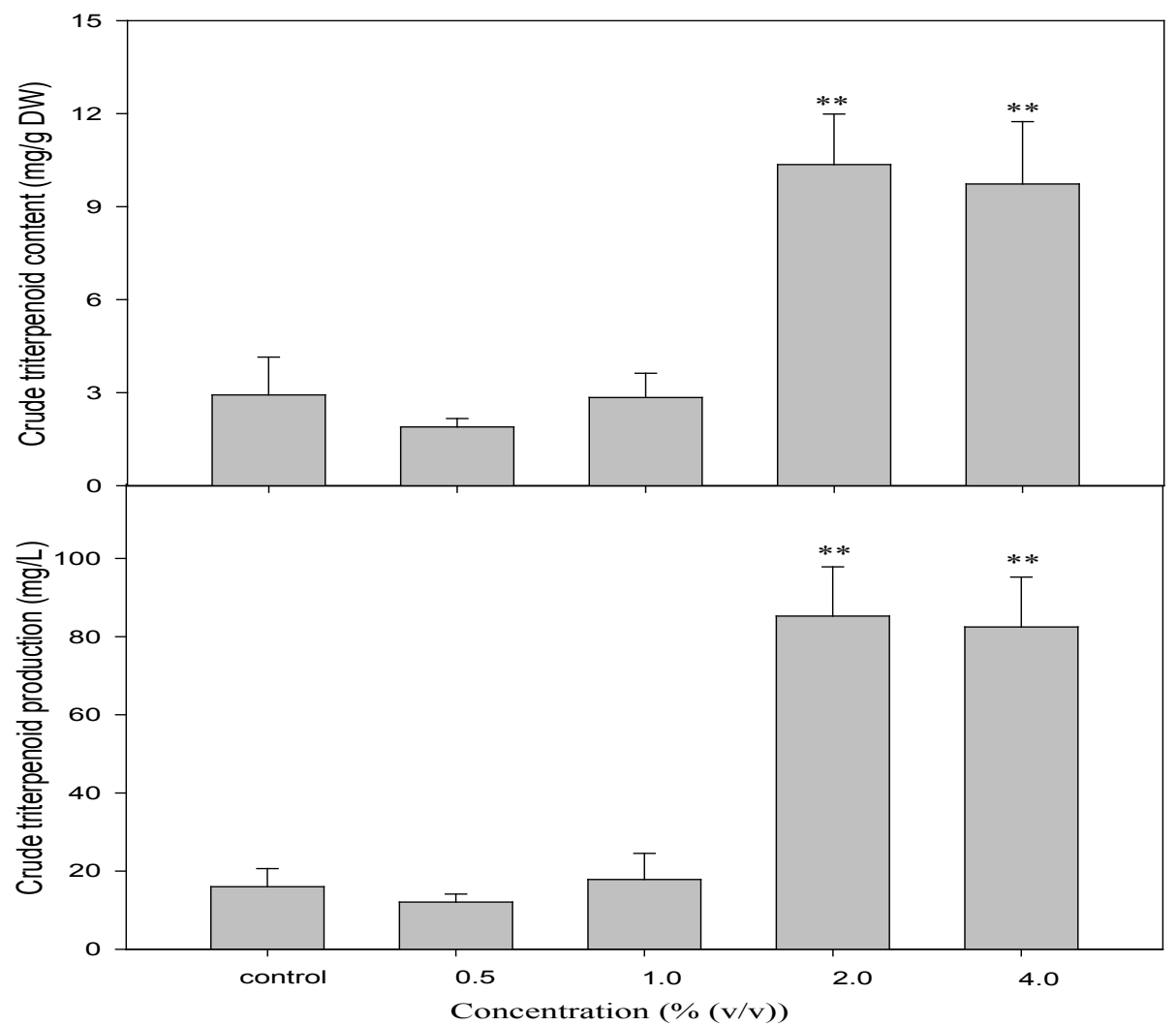

Figure 6: Effect of different concentrations of Astragalus water extract on the content $(\mathrm{A})$ and production $(\mathrm{B})$ of triterpenoid by reusing thin stillage at $25^{\circ} \mathrm{C}$ for 21 days. 
Citation: Ma TW, Yang NJ, Yang FC (2017) Effect of Chinese Herb Extract on the Formation of Triterpenoids in Shake-Flask Cultures of Antrodia cinnamomea. J Bioprocess Biotech 7: 307. doi:10.4172/2155-9821.1000307

Page 6 of 8

\begin{tabular}{|c|c|c|c|c|c|c|c|c|c|c|c|c|}
\hline \multirow{2}{*}{$\begin{array}{l}\text { Chinese herb } \\
\text { kind }\end{array}$} & \multirow[b]{2}{*}{$\begin{array}{l}\mathrm{P} 1_{\max } \\
(\mathrm{mg} / \mathrm{L})\end{array}$} & \multirow[b]{2}{*}{$\begin{array}{l}\mathrm{Q}_{\mathrm{P} 1}(\mathrm{mg} / \\
\text { Lday })\end{array}$} & \multirow[b]{2}{*}{$\begin{array}{c}Y_{p 1 / s} \\
(\mathrm{mg} / \mathrm{g})\end{array}$} & \multirow[b]{2}{*}{$\mathrm{t}$ (day) } & \multicolumn{4}{|c|}{ Total polyphenol } & \multicolumn{4}{|c|}{ Intracellular polysaccharides } \\
\hline & & & & & $\begin{array}{l}\mathrm{P} 2_{\max } \\
(\mathrm{mg} / \mathrm{L})\end{array}$ & $\begin{array}{l}Q_{P 21}(m g / L \\
\text { day) }\end{array}$ & $\mathrm{Y}_{\mathrm{p} 2 / \mathrm{s}}(\mathrm{mg} / \mathrm{g})$ & $\mathrm{t}$ (day) & $\begin{array}{l}\mathrm{P} 3_{\max } \\
(\mathrm{mg} / \mathrm{L})\end{array}$ & $\mathrm{Q}_{\mathrm{P} 3}(\mathrm{mg} / \mathrm{L}$ day $)$ & $Y_{p 3 / s}(m g / g)$ & $\mathrm{t}$ (day) \\
\hline Control & 47.25 & 1.35 & -- & 35 & 115.6 & 3.21 & -- & 35 & 271.6 & 38.80 & -- & 7 \\
\hline Star anise & 73.43 & 3.50 & 7.34 & 21 & 125.9 & 4.50 & 12.59 & 28 & 487.6 & 69.66 & 48.76 & 7 \\
\hline Fagara & 13.87 & 0.66 & 1.39 & 21 & 95.2 & 2.72 & 9.52 & 35 & 342.1 & 48.87 & 34.21 & 7 \\
\hline Astragalus & 85.28 & 4.06 & 8.53 & 21 & 126.3 & 6.02 & 12.63 & 21 & 441.6 & 63.09 & 44.16 & 7 \\
\hline Turmeric & 44.77 & 2.13 & 4.48 & 21 & 93.8 & 2.68 & 9.38 & 35 & 248.2 & 35.46 & 24.82 & 7 \\
\hline Cinnamon & 53.29 & 2.54 & 5.33 & 21 & 116.9 & 3.34 & 11.69 & 35 & 320.5 & 45.79 & 32.05 & 7 \\
\hline
\end{tabular}

Table 1: Comparison of fermentation kinetic parameters in the cultures with the additions of different Chinese herb water extract.

\begin{tabular}{|c|c|c|c|c|c|c|c|c|}
\hline \multirow{2}{*}{ Chinese herb kind } & \multicolumn{4}{|c|}{ Triterpenoid } & \multicolumn{4}{|c|}{ Total polyphenol } \\
\hline & $\mathrm{P} 1_{\max }(\mathrm{mg} / \mathrm{L})$ & $Q_{P 1}(m g / L$ day $)$ & $Y_{p 1 / s}(m g / g)$ & $\mathrm{t}$ (day) & $\mathrm{P} 2_{\max }(\mathrm{mg} / \mathrm{L})$ & $\mathrm{Q}_{\mathrm{P} 21}(\mathrm{mg} / \mathrm{L}$ day $)$ & $\mathrm{Y}_{\mathrm{p} 2 / \mathrm{s}}(\mathrm{mg} / \mathrm{g})$ & $\mathrm{t}$ (day) \\
\hline Control & 47.25 & 1.35 & -- & 35 & 115.6 & 3.21 & -- & 35 \\
\hline 0.5 & 12.08 & 0.58 & 4.83 & 21 & 79.7 & 3.80 & 31.88 & 21 \\
\hline 1 & 17.84 & 0.85 & 3.57 & 21 & 75.5 & 3.60 & 15.10 & 21 \\
\hline 2 & 85.28 & 4.06 & 8.53 & 21 & 126.3 & 6.02 & 12.63 & 21 \\
\hline 4 & 82.46 & 3.93 & 4.12 & 21 & 117.9 & 5.61 & 5.90 & 21 \\
\hline
\end{tabular}

Table 2: Comparison of fermentation kinetic parameters in the cultures with the additions of different concentrations of Astragalus water extract.

(A)

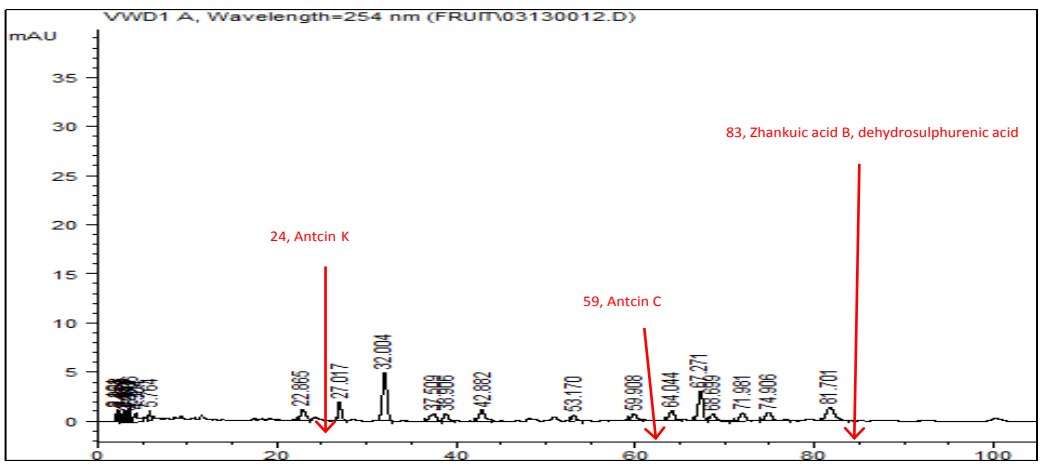

(B)

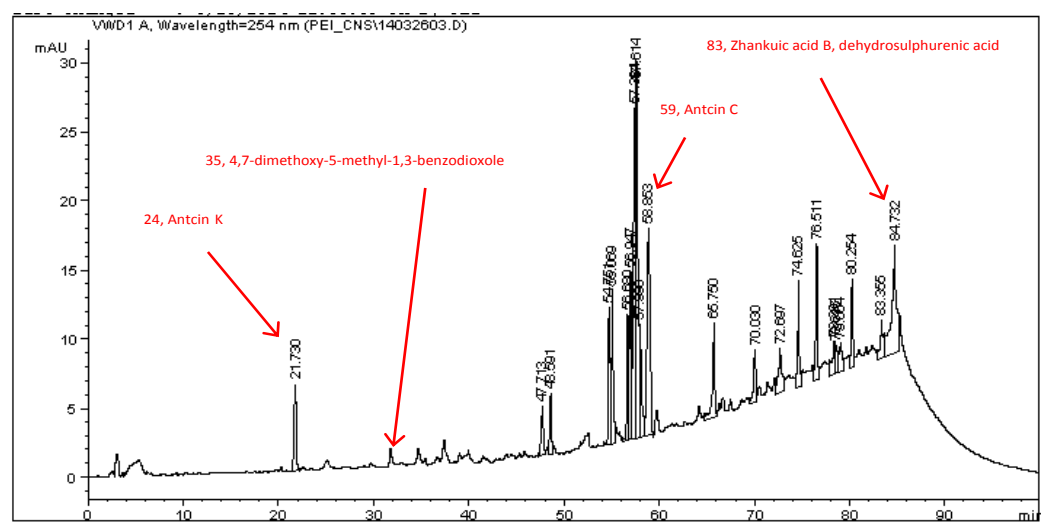

Figure 7: HPLC chromatograms of the ethanolic extracts from cultivated mycelia of $A$. cinnamomea. (A) The mycelia from the during submerged fermentation in ou previous study control culture at $25^{\circ} \mathrm{C}$ for 28 days, (B) the mycelia from the culture with $2 \%$ Astragalus water extract addition at $25^{\circ} \mathrm{C}$ for 21 days

$\mathrm{mg} / \mathrm{L}$ day (the control) to $4.06 \mathrm{mg} / \mathrm{L}$ day, resulting in more than a threefold increase. Yield coefficient also increased to $8.53 \mathrm{mg} / \mathrm{g}$.

With respect to another metabolite of total polyphenol, the Chinese herb water extracts of Star anise and Astragalus were demonstrated to have a positive influence on the formation of total polyphenol. The addition of Astragalus water extract $(2 \%(\mathrm{v} / \mathrm{v}))$ was able to raise the production rate parameter to $6.02 \mathrm{mg} / \mathrm{L}$ day, compared with the control of $3.21 \mathrm{mg} / \mathrm{L}$, and had a two-fold increase. The yield coefficient parameter increased to $12.63 \mathrm{mg} / \mathrm{g}$. Based on the results indicated in Table 1, with respect to the other metabolite of intracellular polysaccharides, Turmeric was the only Chinese herb that had a negative effect. In contrast, Star anise water extract $(2 \%(\mathrm{v} / \mathrm{v}))$ was able to effectively enhance the IPS production rate from $38.8 \mathrm{mg} / \mathrm{L}$ day (the control) to $69.66 \mathrm{mg} / \mathrm{L}$ day, and had more than a 1.8 -fold increase.

As the results indicated in Table 2, when different addition amounts of Astragalus water extract ranging from 0.5 to $4 \%$ (v/v) were compared, the most appropriate level was still found to be around $2 \%$. 
Citation: Ma TW, Yang NJ, Yang FC (2017) Effect of Chinese Herb Extract on the Formation of Triterpenoids in Shake-Flask Cultures of Antrodia cinnamomea. J Bioprocess Biotech 7: 307. doi:10.4172/2155-9821.1000307

Page 7 of 8

\section{HPLC analysis of triterpenoids}

HPLC analyses were according to Chang's paper it displays that the formation of ergostane triterpenoids, such as antcins $\mathrm{C}$ and $\mathrm{K}$, and zhankuic acids A, B and C, is strongly related to the basidiomatal formation of A. cinnamomea [32]. HPLC analyses were performed on mycelia extracts from the shake flask cultures. The resulting profiles are given in Figure 7A and 7B. Figure 7A shows the results of the mycelia extract from our previous study control culture [19]. In the mycelium extract, three ergostane triterpenoid peaks appeared at the retention times of 24, 59 and 83 min (Ancinc K, Ancinc C and zhankuic acids B). These products were formed after 28 days' fermentation, but the content was very little. HPLC chromatograms of the mycelia extract from the addition of $2 \%$ Astragalus water extract culture is presented in Figure $7 \mathrm{~B}$ after 21 days of fermentation. Compared with the mycelia of our previous study control culture, the profiles of HPLC analysis showed that the mycelia cultured with Astragalus water extract addition contained more sorts of triterpenoid. In other words, this result demonstrates that the addition of Astragalus water extract can effectively enhance the production of bioactive metabolites in the submerged culture of $A$. cinnamomea.

\section{Conclusions}

Since a fruiting body of A. cinnamomea grows very slow and its market value reaches approximately twenty thousand US dollars per kilogram, the production of mycelia and bioactive metabolites by A. cinnamomea in submerged cultures has prospered in Taiwan in recent years. In order to enhance production efficiency, the control of environmental conditions or the modification of media composition is vital. Some published papers have demonstrated that the additives extracted from the bark of Cinnamonum kanehirai Hay are effective in enhancing mycelia growth and the production of bioactive compounds [14-17]. However, from plant conservation and large-scale production points of view, finding substitutes for Cinnamonum kanehirai Hay bark are definitely necessary. Among many sources, Chinese herbs are obviously the safest and healthiest source. From a series of experiments, our study demonstrated that the addition of Chinese herb water extracts can effectively enhance the production of biomass and triterpenoid in submerged cultures. In addition, these results demonstrate the feasibility of reusing thin stillage for A. cinnamomea mycelia culture.

\section{Acknowledgements}

The authors wish to thank the Ministry of Science and Technology of Taiwan for financial supports (MOST 104-2221-E-029-020).

\section{References}

1. Chen $\mathrm{CH}$, Yang SW, Shen YC (1995) New steroid acids from Antrodia cinnamomea, a fungal parasite of Cinnamomum micranthum. J Nat Prod 58: 1655-1661.

2. Song TY, Hsu SL, Yeh CT, Yen GC (2005) Mycelia from Antrodia camphorata in submerged culture induce apoptosis of human hepatoma HepG2 cells possibly through regulation of fas pathway. J Agric Food Chem 53: 5559-5564.

3. Cherng IH, Chiang HC, Cheng MC, Wang Y (1995) Three new triterpenoids from Antrodia cinnamomea. J Nat Prod 58: 365-371.

4. Chiang HC, Wu DP, Cherng IW, Ueng CH (1995) A sesquiterpene lactone, phenyl and biphenyl compounds from Antrodia cinnamomea. Phytochem 39: 613-616.

5. Cherng IH, Wu DP, Chiang HC (1996) Triterpenoids from Antrodia cinnamomea. Phytochem 41: 263-267.

6. Geethangili M, Tzeng YM (2011) Review of pharmacological effects of Antrodia camphorata and its bioactive compounds. Evid Based Complement Alternat Med 8: 1-17

7. Yeh CT, Rao YK, Yao CJ, Yeh CF, Li CH, et al. (2009) Cytotoxic triterpenes from Antrodia camphorata and their mode of action in HT-29 human colon cance cells. Cancer Lett 285: 73-79.

8. Dai YY, Chuang CH, Tsai CC, Sio HM, Huang SC, et al. (2003) The protection of Antrodia camphorata against acute hepatotoxicity of alcohol in rats. J Food Drug Anal 11: 177-185.

9. Yang HL, Chen CS, Chang WH, Lu FJ, Lai YC, et al (2006) Growth inhibition and induction of apoptosis in MCF-7 breast cancer cells by Antrodia camphorata. Cancer Lett 231: 215-227.

10. Hseu YC, Chen SC, Chen HC, Liao JW, Yang HL (2008) Antrodia camphorata inhibits proliferation of human breast cancer cells in vitro and in vivo. Food Chem Toxicol 46: 2680-2688.

11. Yang HL, Kuo YH, Tsai CT, Huang YT, Chen SC, et al. (2011) Anti-metastatic activities of Antrodia camphorata against human breast cancer cells mediated through suppression of the MAPK signaling pathway. Food Chem Toxicol 49: 290-298.

12. Chiang CC, Chiang BH (2013) Processing characteristics of submerged fermentation of Antrodia cinnamomea in airlift bioreactor. Biochem Eng J 73 : 65-71.

13. Liu CJ, Chiang CC, Chiang BH (2012) The elicited two-stage submerged cultivation of Antrodia cinnamomea for enhancing triterpenoids production and antitumor activity. Biochem Eng J 64: 48-54.

14. Chang TT, Wang WR (2008) The role of four essential oils on mycelial growth and basidiomatal formation of Antrodia cinnamomea. Taiwan J Forest Sci 23: $105-110$.

15. Shen YC, Chou CJ, Wang YH, Chen CF, Chou YC, et al. (2004) Anti-inflammatory activity of the extracts from mycelia of Antrodia camphorata cultured with watersoluble fractions from five different Cinnamomum species. FEMS Microbiol Let 231:137-143.

16. Sheu SJ, Chen CN, Chen CC (2000) Study on the host specificity of Antrodia camphorata. Taiwan J Agric Chem Food Sci 38: 533-539.

17. Wu SY, Kao YT, Chang TT, Chang ST (2003) Preliminary investigation on the effects of Cinnamomum kanehirae extracts on the mycelial growth of Antrodia camphorata. Q J Chi For 36: 297-306.

18. Yang FC, Ma TW, Chuang YT (2012) Medium modification to enhance the formation of bioactive metabolites in shake flask cultures of Antrodia cinnamomea by adding citrus peel extract. Bioprocess Biosyst Eng 35: 1251-1258.

19. Ma TW, Lai Y, Yang FC (2014) Enhanced production of triterpenoid in submerged cultures of Antrodia cinnamomea with the addition of citrus peel extract. Bioprocess Biosyst Eng 37: 2251-2261.

20. Yang FC, Ma TW, Lee YH (2013) Reuse of citrus peel to enhance the formation of bioactive metabolite-triterpenoid in solid-state fermentation of A. cinnamomea. Biochem Eng J 78: 59-66.

21. Liao H, Banbury LK, Leach DN (2008) Antioxidant activity of 45 Chinese herbs and the relationship with their TCM characteristics. Evid Based Complement Alternat Med 5: 429-434.

22. Craig WJ (1999) Health-promoting properties of common herbs. Am J Clin Nutr 70: 491-499.

23. Xie P, Chen S, Liang Y, Wang X, Tian R, et al. (2006) Chromatographic fingerprin analysis-a rational approach for quality assessment of traditional Chinese herbal medicine. J Chromatogr A 1112: 171-180.

24. Yang FC, Tung HL (1996) Reuse of thin stillage from rice spirit for the culture of the yeast Saccharomyces cerevisiae. Process Biochem 31: 617-620.

25. Yang FC, Maa DW (1998) Fed-batch culture of yeast Saccharomyces cerevisiae with a DO-stat method by a fuzzy controller. Bioprocess Eng 18: 79-82.

26. Yang FC, Lin IH (1998) Production of acid protease using thin stillage from a rice-spirit distillery by Aspergillus niger. Enzyme Microb Technol 23: 397-402.

27. Hsieh C, Hsu TH, Yang FC (2005) Production of polysaccharides of Ganoderma lucidum (CCRC36021) by reusing thin stillage. Process Biochem 40: 909-916. 
Citation: Ma TW, Yang NJ, Yang FC (2017) Effect of Chinese Herb Extract on the Formation of Triterpenoids in Shake-Flask Cultures of Antrodia cinnamomea. J Bioprocess Biotech 7: 307. doi:10.4172/2155-9821.1000307

Page 8 of 8

28. Yang FC (1998) Drying trials of thin stillage from the manufacture of rice spirit. Bioresour Technol 65: 163-165.

29. DuBois M, Gilles KA, Hamilton JK, Rebers PA, Smith F (1956) Colorimetric method for determination of sugars and related substances. Anal Chem 28: 350-356

30. Tsujikura Y, Higuchi T, Miyamoto Y, Sato S (1992) Manufacture of ganoderic acid by fermentation of Ganoderma lucidum. Japan Kokai Tokkyo Koho JP 04304890 .

31. Singleton VL, Rossi JA (1965) Colorimetry of total phenolics with phosphomolybic-phosphotungstic acid reagents. Am J Enol Vitic 16: 144-158.

32. Chang TT, Wang WR, Chou CJ (2011) Differentiation of mycelia and basidiomes of Antrodia cinnamomea using certain chemical components. Taiwan J Forest Sci 26: 125-133.
33. Sinclair S (1998) Chinese herbs: a clinical review of Astragalus, Ligusticum and Schizandrae. Altern Med Rev 3: 338-344.

34. Shao BM, Xu W, Dai H, Tu P, Li Z,et al. (2004) A study on the immune receptors for polysaccharides from the roots of Astragalus membranaceus,a Chinese medicinal herb. Biochem Biophys Res Commun 320: 1103-1111.

35. Kuban M, Öngen G, Khan IA, Bedir E (2013) Microbial transformation of cycloastragenol. Phytochem 88: 99-104.

36. Kuban M, Öngen G, Bedir E (2010) Biotransformation of cycloastragenol by Cunninghamella blakesleeana NRRL 1369 resulting in a novel framework. Org Lett 12: 4252-4255.

37. Bedir E, Kula C, Öner Ö, Altaş M, Tağ Ö, et al. (2015) Microbial transformation of Astragalus sapogenins using Cunninghamella blakesleeana NRRL 1369 and Glomerella fusarioides ATCC 9552. J Mol Catal B: Enzym 115: 29-34. 